\title{
Does the probabilistic maturation reaction norm approach disentangle phenotypic plasticity from genetic change?
}

\author{
S. B. M. Kraak* \\ Wageningen IMARES (Institute for Marine Resources and Ecosystem Studies), Wageningen UR, PO Box 68, 1970 AB, \\ IJmuiden, The Netherlands
}

\begin{abstract}
Two-dimensional probabilistic maturation reaction norms (PMRNs) define the probability that individuals mature as a function of age and size. PMRNs have recently been used to derive empirical support for the hypothesis that high fishing mortality has induced genetic change towards earlier maturation in exploited populations. However, the 2-dimensional PMRN method does not, strictly speaking, disentangle phenotypic plasticity from genetic change in maturation. Instead, it disentangles the contribution of variation in growth and mortality from other sources of variation contributing to changes in maturation. After removing the contribution of variation in growth and mortality, any remaining change is not necessarily purely genetic. Environmental factors may exist that directly affect the propensity to mature at a certain size and age. An observed trend in the sizeage PMRN may therefore be partly or fully explained by a co-incidental trend in an (environmental) factor. As pointed out by Grift et al. (2007; Mar Ecol Prog Ser 334:213-224), such co-dependence is captured conceptually by multi-dimensional PMRNs, as opposed to 2-dimensional (size-age) PMRNs, where the higher dimensions represent the relevant variables. Dimensions that may partly or fully explain the observed trends in size-age PMRNs, other than evolution, include temperature, polluting endocrine-disrupting chemicals, the social structure of the population, and body condition; changes in the last two may be fisheries-induced. To illustrate these views, I re-analysed data on North Sea plaice, and demonstrated that temperature explains part of the shift in the size-age PMRN but that a residual shift remains. The latter finding supports the hypothesis of genetic change.
\end{abstract}

KEY WORDS: Probabilistic maturation reaction norms - Fisheries-induced evolution · Phenotypic plasticity $\cdot$ Maturation process

\section{INTRODUCTION}

During the last few decades, a number of studies have drawn attention to fisheries-induced adaptive genetic shifts in life history traits (e.g. Borisov 1978, Law \& Grey 1989, Rijnsdorp 1993, Law 2000, Conover \& Munch 2002, Heino et al. 2002a, Ernande et al. 2004). One of the best studied phenomena is that high fishing mortality produces a selection pressure favouring maturation earlier in life owing to a reduction in life-span expectancy (e.g. Borisov 1978, Law \& Grey 1989, Rijnsdorp 1993, Ernande et al. 2004). This idea is conceptually straightforward: if the mortality rate of adults is high, individuals that are genetically predisposed to early maturation will have a higher chance of reproducing and passing on their genes to the next generation than late-maturing individuals. Progress in this field of research was made due to the development of a statistical technique (Heino et al. 2002b) through which so-called probabilistic maturation reaction norms (PMRNs) are determined from population data on age, length and maturity status of individual fish. PMRNs define the probability that an individual matures as a function of its age and size (Fig. 1a). Application of the PMRN method provided support for the hypothesis that fisheries-induced evolutionary 
changes in age and size at maturation have occurred in some important exploited fish populations on contemporary time scales, e.g. in Atlantic cod (Heino et al. 2002a, Barot et al. 2004, Olsen et al. 2004, 2005), North
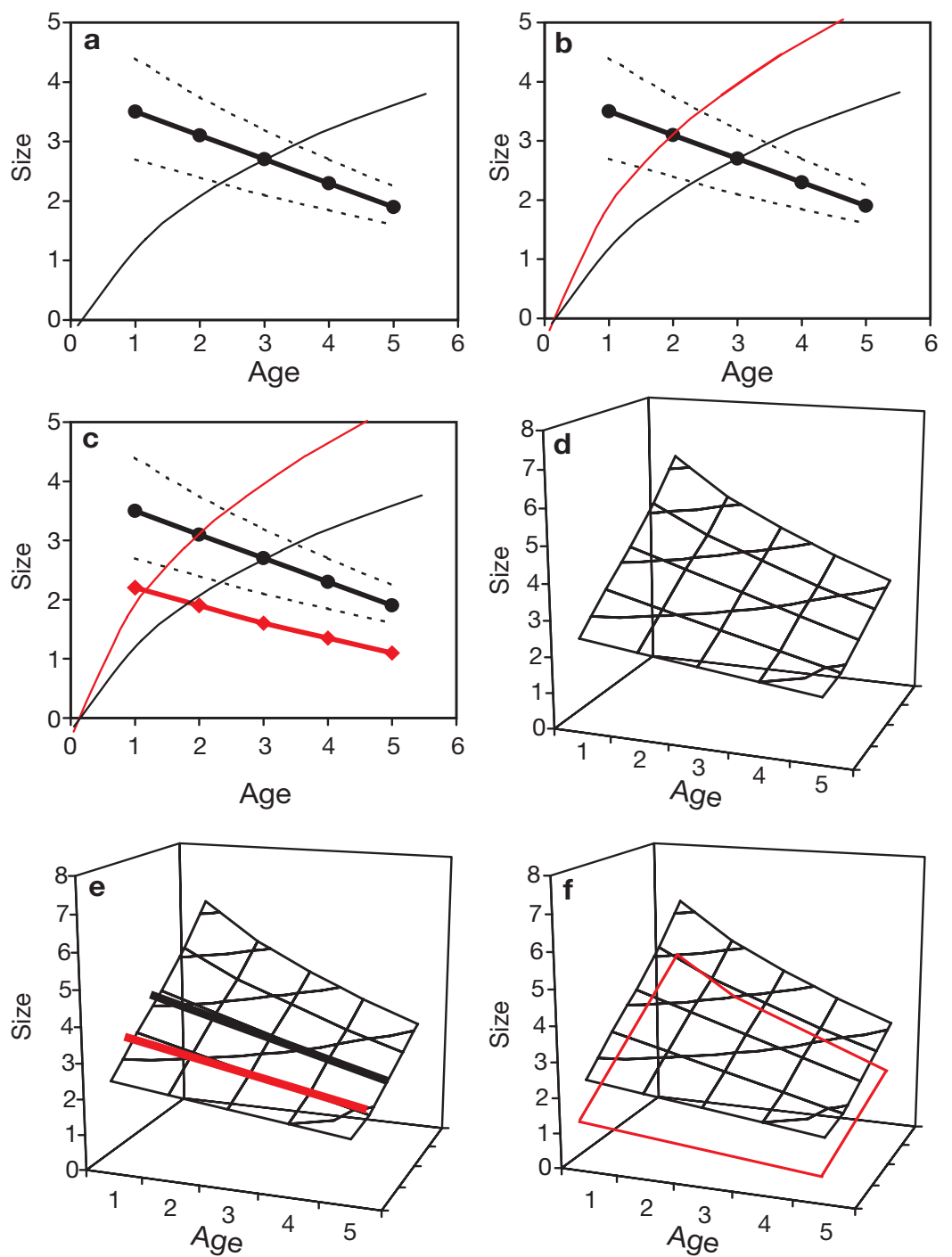

Fig. 1. $(\mathrm{a}-\mathrm{c})$ 2-dimensional probabilistic maturation reaction norms (PMRNs), defining the probability that an individual matures as a function of its age and size, and (d-f) 3-dimensional PMRNs, defining the probability that an individual matures as a function of its age, size and state along a 3rd dimension (e.g. condition or temperature). This is an illustration of the concept: no actual data were used. Straight solid black and red lines represent combinations of age and size at which the probability of maturing is $50 \%$. Broken lines represent combinations of age and size at which the probability of maturing is 10 and $90 \%$, respectively. Curved red and black lines represent average growth curves. Black and red planes represent combinations of age and size and state along the 3rd dimension at which the probability of maturing is $50 \%$. Above and below these planes, planes can be envisaged as representing states at which the probability of maturing is for example 90 and $10 \%$, respectively. (a) 2-dimensional PMRN, (b) 2-dimensional PMRN and increased growth rate (red curve), (c) shifted 2-dimensional PMRN (red straight line), (d) 3-dimensional PMRN, (e) 3-dimensional PMRN on which the size-age PMRN 'slid down' along the 3rd dimension (red straight line), (f) shifted 3-dimensional PMRN (red plane)
Sea plaice (Grift et al. 2003) and American plaice (Barot et al. 2005). Fisheries management bodies are being advised to consider these effects of fishing Browman 2000, Law 2000, Pauly et al. 2002) because a shift towards earlier maturation will lead to smaller average adult size, thereby lowering yields. Because genetic changes may be irreversible or can only be reversed over a much longer time period than that in which they were brought about (Law \& Grey 1989), the consequences are long-lasting.

Let me describe the context in which the PMRN method was developed. Several decades ago it was found that, in some heavily fished populations, the age at maturation had declined (Trippel 1995). Three hypotheses were brought forward to link the shift to the high fishing mortality (e.g. Rijnsdorp 1993, Heino et al. 2002a, Grift et al. 2003, Barot et al. 2004, 2005). The first hypothetical cause is a demographic effect of high fishing mortality. In this case, the population simply became more dominated by younger and smaller individuals, while late-maturing fish were lost. According to the second hypothesis of phenotypic plasticity, the fish may have responded to the lower density of the heavily fished population and the associated greater food availability by growing faster. These faster-growing fish would simply reach the stage of maturation at an earlier age (Fig. 1b). The third hypothesis states that fish that were genetically predisposed to mature at a younger age and a smaller size were favoured by selection caused by high fishing mortality. These 3 hypotheses are not mutually exclusive. The method of PMRNs (Heino et al. 2002a,b,c) takes account of the first 2 effects, because it quantifies the probability of maturing conditional on a fish reaching a certain size at a certain age. This way, any effect that remains is likely to be a result of genetic change. Authors that used this method advertised it as a powerful approach that helps to disentangle the effect of phenotypic plasticity from the effect of genetic change (Fig. 1b,c; Heino et al. 2002a,c, Grift et al. 2003, Barot et al. 2004, 2005, Engelhard \& Heino 2004, Olsen et al. 2005).

In this essay, I caution against drawing too strong an inference from the application of the PMRN method and question to what ex- 
tent the method enables the disentanglement of phenotypic plasticity from genetic change. Even some authors who used the method previously expressed some caution in this regard (Heino et al. 2002a,c, Grift et al. 2003, Barot et al. 2004, 2005, Olsen et al. 2004, 2005). In the next section, I argue that environmental variables other than those that affect maturation through growth need to be taken into account. In the subsequent section this is illustrated through an example. The essay concludes with an answer to the questions raised in the title.

\section{PHENOTYPIC PLASTICITY VS. GENETIC CHANGE}

The PMRN method disentangles the contribution of variation in growth and survival from other sources of variation that contribute to changes in maturation (Olsen et al. 2005). This is not the same as disentangling phenotypic plasticity in maturation from genetic variation in maturation. Firstly, although variation in growth may have an important environmental component, it will often also have a genetic component (e.g. Conover \& Munch 2002, Heino et al. 2002c). A population could hypothetically respond to fishing pressure genetically with faster growth (faster-growing fish would reach maturity earlier and thereby have a selective advantage) or slower growth (slower-growing fish delay exposure to capture; Sinclair et al. 2002a,b). More importantly however, it will not necessarily be the case that after removing the contribution of the variation in growth and mortality, any remaining change-observed as a shift in the PMRN in size-age space (Fig. 1c) - is purely genetic. Instead, environmental factors may exist that directly affect the propensity to mature at a certain size and age (Heino et al. 2002a,c, Grift et al. 2003, Barot et al. 2004, 2005, Olsen et al. 2004, 2005). Grift et al. (2007) thus introduced a multi-dimensional PMRN as opposed to a 2-dimensional (size-age) PMRN, where the higher dimensions represent the relevant environmental variables. An application of this approach (provided by Grift et al. 2007) used body condition as the third explanatory variable to characterize the probability of maturing. A 3-dimensional PMRN consists of a plane (Fig. 1d) instead of a line (Fig. 1a), which connects states in which fish with a given genetic predisposition would have a $50 \%$ probability of maturing.

A potential additional or alternative explanatory variable (Heino et al. 2002b,c, Olsen et al. 2004, 2005), which can be represented as an additional dimension, could be temperature. Temperature may have an effect on the probability of maturing by itself, independent of its effect via growth (Grift et al. 2003, Dembski et al. 2006). A fish that had grown at a certain rate, such that it had reached a certain size at a certain age, may have different probabilities of maturing depending on the temperature experienced. It remains to be shown whether globally increasing water temperatures have contributed to any of the published shifts in PMRNs (Fig. 1c,e).

Another candidate variable that has probably changed globally and more or less unidirectionally over the last few decades is the concentration of polluting chemicals in the water. Endocrine-disrupting chemicals (Zala \& Penn 2004) may influence the tendency to mature (Devlin \& Nagahama 2002). Social factors could also have an effect: in some fish species, the probability of maturing at a given size and age depends on the social structure and size composition of the local population (Fricke \& Fricke 1977, Hobbs et al. 2004), but it is not known whether this is the case in those exploited species in which PMRNs have been investigated. The social structure of exploited fish populations may have changed as a result of fishing, e.g. through its effect on population density (Rowe \& Hutchings 2003), on the size and age composition, and on the sex ratio in cases where fishing mortality affects the sexes differentially (Kell \& Bromley 2004). The probability of maturing at a given length and age may also depend on body condition (Bromley 2000, Grift et al. 2007). Environmental changes (e.g. increased food availability resulting from fisheries-induced population decline) may have caused a trend in condition. If adopting the 2-dimensional view, one would perhaps infer genetic change (Fig. 1c), but in fact the hypothesis of a plastic response to environmental changes that affected condition would not have been excluded. The 2-dimensional PMRN may just have 'slid down' on the plane of the 3-dimensional PMRN in the direction of higher condition (Fig. 1e).

Hence, an observed shift in the PMRN in size-age space (Fig. 1c) is not conclusive evidence that a genetic change has taken place, or is the only cause, because the possibility of a phenotypically plastic response to environmental changes other than via growth (Fig. 1e,f) has not been excluded. It remains to be investigated whether trends in temperature, pollutants, social structure, condition or other variables coincided with any observed trend in the PMRN. An aim for researchers in this field could be to quantify the relative importance of candidate factors to the observed trend.

\section{TEMPERATURE AND MATURATION IN NORTH SEA PLAICE}

I report here a re-working of the data used by Grift et al. (2003). Grift et al. (2003) applied the 2-dimensional PMRN method to females of 41 cohorts (from 1955 to 1995) of North Sea plaice Pleuronectes platessa L., and 
found that the PMRN for age and length at maturation had significantly shifted towards younger age and smaller length (Fig. 1c). They concluded that this longterm trend suggests a genetic response. They also observed short-term fluctuations superimposed on the long-term trend, and showed that these could be partly explained by short-term variations in temperature. For all ages, the probability of maturing at a given length increased significantly with the temperature experienced 2 and 3 yr prior to the year in which the maturity status of the fish was assessed. These lags were used because a previous analysis (Rijnsdorp 1993) had indicated that growth 2 and 3 yr earlier may affect maturation. Temperature itself exhibited a significant temporal trend (an average increase of $0.02^{\circ} \mathrm{C}$ per year, Fig. 2), but Grift et al. (2003) removed this trend because they wanted to analyse the short-term effect of temperature. However, in the context of the argument advocated in this essay, the trend seen in the 2dimensional PMRN may be partly caused by this trend in temperature. The probability of maturing at a particular age and length may have increased as a result of increased temperature: the size-age PMRN may have 'slid down' on the plane of the 3-dimensional PMRN in the direction of higher temperature (Fig. 1e). In that case, not only the short-term fluctuations but also the long-term trend of the size-age PMRN may be partly explained by changes in water temperature. Only if a trend in the size-age PMRN remains after removal of the effect of temperature does the evidence support a genetic response (Fig. 1f).

I analysed the yearly PMRN midpoints $\left(L_{\mathrm{p} 50}\right.$, the length at which the probability of maturing equals $50 \%$ ) for each of the Ages 2 to 6 yr. I tested with simple regression whether the midpoints were correlated with

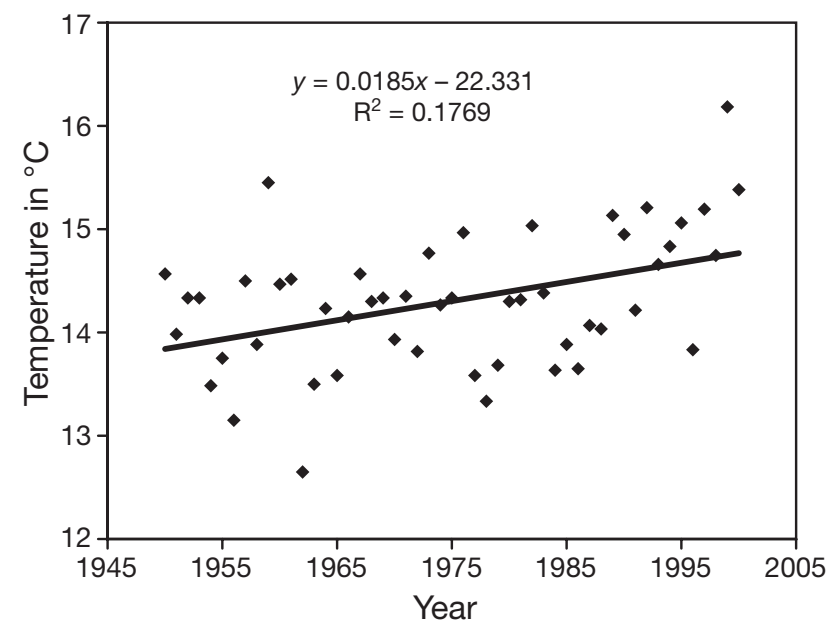

Fig. 2. Average daily temperature during the 2nd and 3rd quarter of the year measured at a fixed time of day at Den Helder (theNetherlands) after correction for the tidal phase; $\mathrm{p}=0.002$ the average temperature of the second quarter of the year before the maturity status of the fish was assessed $\left(t_{\mathrm{yr}-1}\right)$. North Sea plaice start their maturation process around July of the year before the spawning season, which extends from January to March (Rijnsdorp \& Witthames 2005). I hypothesised that the temperature just prior to the onset of maturation may affect the probability of maturing. If the effect was significant, I removed this effect and tested whether the remaining variation (i.e. the residuals of the regression) was correlated with the average temperature of the 2nd and $3 r d$ quarter 2 yr prior $\left(t_{\mathrm{yr}-2}\right)$. If that effect was significant, I also removed that effect and tested whether the remaining variation correlated with the 2 nd and $3 \mathrm{rd}$ quarter temperature $3 \mathrm{yr}$ prior $\left(t_{\mathrm{yr}-3}\right)$. If that effect too was significant, it was also removed and I tested whether the remaining variation correlated with the year of birth of the cohort. Similarly to Grift et al. (2003), I chose to test the effects of $t_{\mathrm{yr}-2}$ and $t_{\mathrm{yr}-3}$ because previous analysis (Rijnsdorp 1993) indicated that growth 2 and 3 yr earlier may affect maturation. The exact statistical treatment (e.g. in what order to remove effects, whether and how to deal with the autocorrelation of the annual temperatures, whether Bonferroni correction [Rothman 1990] is desirable) should depend on the hypothesised mechanisms of the influences of temperature at different times in development. I do not explicitly formulate candidate mechanisms here because this is outside the scope of this study; I merely want to emphasize the importance of exploring alternative explanations for shifts in PMRNs, with the analysis of the North Sea plaice data as an illustration.

Values of $t_{\mathrm{yr}-1}$ only correlated with the probability of maturing for Ages 3 and 6 yr (Table 1). An increase of $1^{\circ} \mathrm{C}$ corresponded to a decrease in the $L_{\mathrm{p} 50}$ of $1.4 \mathrm{~cm}$ for Age $3 \mathrm{yr}$ and $1.3 \mathrm{~cm}$ for Age $6 \mathrm{yr}$. For all ages except Age $6 \mathrm{yr}, t_{\mathrm{yr}-2}$ correlated significantly with the probability of maturing after removal of significant effects (Table 1). An increase of $1^{\circ} \mathrm{C}$ corresponded to decreases varying from $3.8 \mathrm{~cm}$ to $1.1 \mathrm{~cm}$ in the $L_{\mathrm{p} 50}$. For Ages 3 and $4 \mathrm{yr}$, an additional significant effect of $t_{\mathrm{yr}-3}$ was found (Table 1): the $L_{\mathrm{p} 50}$ decreased by 1.6 and 1.0 $\mathrm{cm}$, respectively, with an increase of $1^{\circ} \mathrm{C}$. With these significant effects removed, the probability of maturing still significantly correlated negatively with cohort birth year for all ages. Hence, after taking the influence of temperature experienced 1, 2 and 3 yr earlier into account, there remained a time trend in the $L_{\mathrm{p} 50}$. For fish of Age 2 yr the $L_{\mathrm{p} 50}$ decreased by $0.16 \mathrm{~cm} \mathrm{yr}^{-1}$, for Ages 3 and 4 yr by $0.09 \mathrm{~cm} \mathrm{yr}^{-1}$, and for Ages 5 and 6 yr by $0.10 \mathrm{~cm} \mathrm{yr}^{-1}$ (Table 1 ).

Two conclusions can be drawn from this re-analysis. First, the trend in the PMRN for North Sea plaice as observed by Grift et al. (2003) can indeed be partly 
Table 1. Pleuronectes platessa. Correlations of probabilistic maturatiom reaction norm (PMRN midpoints with $t_{\mathrm{yr}-1}, t_{\mathrm{yr}-2,} t_{\mathrm{yr}-3}$ and cohort after successive removals of significant effects (at $\alpha=0.05$ ) (see section 'Temperature and maturation in North Sea plaice'). Slopes of significant regressions (at $\alpha=0.05$ ) are given in bold; na: not applicable (Age 2 yr fish not yet born); p-values given in parentheses

\begin{tabular}{|lccccc|}
\hline Correlates & Age 2 & Age 3 & Age 4 & Age 5 & Age 6 \\
\hline$t_{\mathrm{yr}-1}$ & $(0.2)$ & $\mathbf{- 1 . 4}(0.02)$ & $(0.16)$ & $(0.08)$ & $\mathbf{- 1 . 3}(0.02)$ \\
$t_{\mathrm{yr}-2}$ & $\mathbf{- 3 . 8}(0.01)$ & $\mathbf{- 1 . 8}(0.007)$ & $\mathbf{- 1 . 4}(0.004)$ & $\mathbf{- 1 . 1}(0.05)$ & $(0.07)$ \\
$t_{\mathrm{yr}-3}$ & na & $\mathbf{- 1 . 6}(0.008)$ & $\mathbf{- 1 . 0}(0.02)$ & $(0.12)$ & $(0.13)$ \\
Cohort & $\mathbf{- 0 . 1 6}(0.02)$ & $\mathbf{- 0 . 0 9}(0.002)$ & $\mathbf{- 0 . 0 9}\left(6 \times 10^{-7}\right)$ & $\mathbf{- 0 . 1 0}\left(4 \times 10^{-5}\right)$ & $\mathbf{- 0 . 1 0}(0.003)$ \\
\hline
\end{tabular}

explained by temperature changes over that time period (Fig. 1e). These results do not contradict the findings of Grift et al. (2003). These authors also demonstrated the effect of temperature; however, they did not test whether temperature changes can partly explain the trend in the 2-dimensional PMRN. My analysis of the effect of temperature is a preliminary exploration. Future work may address questions such as why the effect of $t_{\mathrm{yr}-1}$ is found only for Ages 3 and 6 $\mathrm{yr}$, and by what mechanism is the probability to mature influenced by the temperature experienced immediately prior to the onset of maturation. Other questions remain as well, such as whether $t_{\mathrm{yr}-2}$ and $t_{\mathrm{yr}-3}$ affect the probability of maturing via their effect on growth during earlier development. Second, the effects of temperature are not sufficient to explain the observed trend in PMRN. A residual trend in time remains, and therefore the hypothesis that fisheries-induced genetic change has occurred still receives support (Fig. 1f). The support for this hypothesis increased through this analysis compared to basing it on the findings of Grift et al. (2003) alone, because some effects that might have been alternative explanations for the shifted PMRN have been removed.

Another illustration of how to deal with additional or alternative explanatory factors is provided by the study on North Sea plaice by Grift et al. (2007), where variation in body condition was taken into account. The fact that the 3-dimensional PMRN in size-age-condition space shifted significantly over time (Fig. 1f) lends further support to the genetic-change hypothesis than it received from the findings of Grift et al. (2003) alone.

\section{CONCLUSION}

Does the PMRN approach disentangle phenotypic plasticity from genetic change? No, total disentanglement cannot be reached, and yes, it certainly helps disentanglement. It is impossible to identify and quantify the effects of all the non-genetic candidate factors that may possibly influence maturation, such that any residual trends could be assumed to reflect only genetic change. However, on the positive side, the PMRN approach can make good progress along the never-ending road towards disentanglement, especially when more factors are considered. The continuing challenge remains to design and carry out studies aimed at obtaining ever-more insight into the complex causation of changes in maturation, but science will never reveal all the details. In my opinion, there lies great promise in the open-minded use of the multidimensional PMRN approach and variations thereof when tackling the challenge of disentangling causes of changes in maturation.

Acknowledgements. I thank C. T. Marshall for the invitation to contribute to this Theme Section. I thank A. D. Rijnsdorp and R. E. Grift for discussions and reviewing earlier versions of the manuscript. U. Dieckmann, M. Heino, B. Ernande, P. Bromley, M. Dickey-Collas, A. M. de Roos, F. Mollet, and B. Mundwiler are thanked for discussions and C. T. Marshall, H. Browman, and B. McAdam for their comments on the manuscript.

\section{LITERATURE CITED}

Barot S, Heino M, O'Brien L, Dieckmann U (2004) Long-term trend in the maturation reaction norm of two cod stocks. Ecol Appl 14:1257-1271

Barot S, Heino M, Morgan MJ, Dieckmann U (2005) Maturation of Newfoundland American plaice (Hippoglossoides platessoides): long-term trends in maturation reaction norms despite low fishing mortality? ICES J Mar Sci 62: $56-64$

Borisov VM (1978) The selective effect of fishing on the population structure of species with long life cycle. J Ichthyol 18:896-904

Bromley PJ, Ravier C, Witthames PR (2000) The influence of feeding regime on sexual maturation and atresia in firsttime spawning turbot. J Fish Biol 56:264-278

Browman HI (2000) Application of evolutionary theory to fisheries science and stock assessment-management. Mar Ecol Prog Ser 208:299

Conover DO, Munch SB (2002) Sustaining fisheries yields over evolutionary time scales. Science 297:94-96

Dembski S, Masson G, Monnier D, Wagner P, Pihan JC (2006) Consequences of elevated temperatures on life-history traits of an introduced fish, pumpkinseed Lepomis gibbosus. J Fish Biol 69:331-346

Devlin RH, Nagahama Y (2002) Sex determination and sex differentiation in fish: an overview of genetic, physio- 
logical, and environmental influences. Aquaculture 208: 191-364

Engelhard GH, Heino M (2004) Maturity changes in Norwegian spring-spawning herring Clupea harengus: compensatory or evolutionary responses? Mar Ecol Prog Ser 272: 245-256

Ernande B, Dieckmann U, Heino M (2004) Adaptive changes in harvested populations: plasticity and evolution of age and size at maturation Proc R Soc Lond B 271:415-423

Fricke HW, Fricke S (1977) Monogamy and sex change by aggressive dominance in a coral reef fish. Nature 266: 830-832

Grift RE, Rijnsdorp AD, Barot S, Heino M, Dieckmann U (2003) Trends in reaction norms for maturation in the North Sea plaice. Mar Ecol Prog Ser 257:247-257

Grift RE, Heino M, Rijnsdorp AD, Kraak SBM, Dieckmann U (2007) Three-dimensional maturation reaction norms for North Sea plaice. Mar Ecol Prog Ser 334:213-224

Heino M, Dieckmann U, Godø OR (2002a) Reaction norm analysis of fisheries-induced adaptive change and the case of the Northeast Arctic cod. ICES CM 2002/Y:14

Heino M, Dieckmann U, Godø OR (2002b) Measuring probabilistic reaction norms for age and size at maturation. Evolution 56:669-678

Heino M, Dieckmann U, Godø OR (2002c) Estimating reaction norms for age and size at maturation with reconstructed immature size distributions: a new technique illustrated by application to Northeast Arctic cod. ICES J Mar Sci 59:562-575

Hobbs JPA, Munday PL, Jones GP (2004) Social induction of maturation and sex determination in a coral reef fish. Proc R Soc Lond B 271:2109-2114

Kell LT, Bromley PJ (2004) Implications for current management advice for North Sea plaice (Pleuronectes platessa L.): Part II. Increased biological realism in recruitment, growth, density-dependent sexual maturation and the impact of sexual dimorphism and fishery discards. J Sea Res 51:301-312

Law R (2000) Fishing, selection, and phenotypic evolution. ICES J Mar Sci 57:659-668

Editorial responsibility: Howard Browman (Associate Editorin-Chief), Storebø, Norway
Law R, Grey DR (1989) Evolution of yields from population with age-specific cropping. Evol Ecol 3:343-359

Olsen EM, Heino M, Lilly GR, Morgan MJ, Brattey J, Ernande B, Dieckmann U (2004) Maturation trends indicative of rapid evolution preceded the collapse of northern cod. Nature 428:932-935

Olsen EM, Lilly GR, Heino M, Morgan MJ, Brattey J, Dieckmann U (2005) Assessing changes in age and size at maturation in collapsing populations of Atlantic cod (Gadus morhua). Can J Fish Aquat Sci 62:811-823

Pauly D, Christensen V, Guenette S, Pitcher TJ, Sumaila UR, Walters CJ, Watson R, Zeller D (2002) Towards sustainability in world fisheries. Nature 418:689-695

Rijnsdorp AD (1993) Fisheries as a large scale experiment on life history evolution: disentangling phenotypic and genetic effects in changes in maturation and reproduction of North Sea plaice, Pleuronectes platessa L. Oecologia 96: 391-401

Rijnsdorp AD, Witthames PR (2005) Ecology of reproduction. In: Gibson RN (ed) Flatfish biology and exploitation. Academic Press, London, p 68-93

Rothman KJ (1990) No adjustments are needed for multiple comparisons. Epidemiology 1:43-46

Rowe S, Hutchings JA (2003) Mating systems and the conservation of commercially exploited marine fish. Trends Ecol Evol 18:567-572

Sinclair AF, Swain DP, Hanson JM (2002a) Disentangling the effects of size-selective mortality, density, and temperature on length-at-age. Can J Fish Aquat Sci 59: 372-382

Sinclair AF, Swain DP, Hanson JM (2002b) Measuring changes in the direction and magnitude of size-selective mortality in a commercial fish population. Can J Fish Aquat Sci 59:361-371

Trippel EA (1995) Age at maturity as a stress indicator in fisheries. BioScience 45:759-771

Zala SM, Penn DJ (2004) Abnormal behaviours induced by chemical pollution: a review of the evidence and new challenges. Anim Behav 68:649-664

Submitted: February 2, 2006; Accepted: December 11, 2006 Proofs received from author(s): April 3, 2007 